\title{
Project for Residues Valorisation and Reutilization from an 0xy-Combustion Circulating Fluidized Bed Boiler with $\mathrm{CO}_{2}$ Capture
}

\author{
Jose A. Gutierrez Bravo, Raquel García \\ Department of Mining Engineering, Universidad de León, Campus de Vegazana, León, Spain \\ Email: jabutbr@unileon.es
}

How to cite this paper: Bravo, J.A.G. and García, R. (2019) Project for Residues Valorisation and Reutilization from an Oxy-Combustion Circulating Fluidized Bed Boiler with $\mathrm{CO}_{2}$ Capture. Journal of Power and Energy Engineering, 7, 19-26. https://doi.org/10.4236/jpee.2019.71002

Received: October 19, 2018

Accepted: January 1, 2019

Published: January 4, 2019

Copyright $\odot 2019$ by authors and Scientific Research Publishing Inc. This work is licensed under the Creative Commons Attribution International License (CC BY 4.0).

http://creativecommons.org/licenses/by/4.0/

\begin{abstract}
Power generation industry has tackled waste reuse and valorisation for decades. Nevertheless, new technologies, like Circulating fluidized bed (CFB) boilers operating in oxy-combustion, have an important gap of knowledge in residues characterization and valorisation. This project will tackle this. Furthermore, as a result of the high quantity of waste that these installations generate new business models can be opened. The project aims at characterizing the residues from a large scale oxy-CFB facility with carbon, capture, use and storage (CCUS) focusing on the larger and main residues produced: fly ash, bottom ash, and algae production from captured $\mathrm{CO}_{2}$. An analysis of possible uses and treatment needs, such as additives or preparation for use in agriculture or industry, will be carried out. Best re-utilization and valorisation options will be stated for fly ash, bottom ash and algae, aiming for a novel combination of $\mathrm{CO}_{2}$ capture technologies with recovery of valuable materials from different wastes, addressing different and sustainable solutions for their reuse, enhancing the feasibility of CCUS, and combining research with the creation of new business models towards a green economy more attractive to the public perception.
\end{abstract}

\section{Keywords}

Coal Residues Valorization, Coal Ash, CCUS, Oxycombustion

\section{Introduction}

Carbon dioxide $\left(\mathrm{CO}_{2}\right)$ is the primary greenhouse gas (GHG) emitted through human activities and its concentration to the atmosphere has risen faster than 
ever in the last century. Carbon Capture and Storage (CCUS) technologies are one of the available technologies to mitigate GHG emissions from large-scale fossil fuel usage recognized by the Zero Emissions Platform (ZEP) and the 2050 European Energy Roadmap [1] to mitigate this increase, providing a bridge between our present coal-based energy and a low-carbon energy future. CCUS aims for the reutilisation and valorisation of captured $\mathrm{CO}_{2}$ to accelerate advancements and widespread deployment combined with social and environmental benefits. Oxy-combustion with $\mathrm{CO}_{2}$ capture, use and storage is one of the leading and most cost-effective carbon reduction technologies, which has proved its potential for industrial scale power production and for retrofitting existing power stations. The basic principle of oxy-combustion is to replace the traditional oxidant (Air: 21\% Oxygen, 79\% Nitrogen) with a mixture of pure oxygen and recycled $\mathrm{CO}_{2}$-rich gas to produce a flue gas enriched with $\mathrm{CO}_{2}$.

Power generation industry has tackled waste reuse and valorisation for decades. Nevertheless, new technologies, like CFB boilers operating in oxy-combustion, have an important gap of knowledge in residues characterization and valorisation. This project will tackle this.

\section{Objectives}

The project idea aims at characterizing the residues from a large scale oxy-CFB facility with CCUS focusing on the larger and main residues produced: fly ash, bottom ash (solid residues) and algae production from captured $\mathrm{CO}_{2}$. An analysis of possible uses and treatment needs (such as additives or preparation for use in agriculture or industry) will be carried out, which will develop innovative and breakthrough solutions for the recovery, preparation and reuse of residues.

Best re-utilization and valorisation options will be stated to be carried out under real conditions for fly ash, bottom ash and algae. The aim is a novel combination of $\mathrm{CO}_{2}$ capture technologies with recovery of valuable materials from several wastes, while addressing different and sustainable solutions for their reuse. It will enhance the feasibility of CCUS, combining research with the creation of new business models towards a green economy more attractive to the public perception.

\section{Scientific and Technical objectives}

The overall objective of the project is the reduction of the environmental impacts produced by oxy-CFB boilers with $\mathrm{CO}_{2}$ capture and reuse. To achieve this objective, innovative cutting-edge solutions will be developed. These solutions will involve:

- The characterization of fly ash and bottom ash of the largest scale existing CFB boiler, under oxy-combustion of different coals, biomass and mixtures. Furthermore, captured $\mathrm{CO}_{2}$ characterization in this facility will be performed, to see its affection on algae production.

- The valorisation options as raw materials for other industries, construction, soils restoration, reforestation and agriculture will be identified for solid 
residues (fly ash and bottom ash) and algae from captured $\mathrm{CO}_{2}$ from CFB oxy-combustion.

- Field tests for the most promising options of reutilization and valorisation.

- The development of risk assessment and techno-economic analysis and recommendations, with new business models for reuse-oriented services for an efficient management of residues as raw materials for specific applications.

The project idea aims at reducing the demand for raw materials on industry, construction, soils restoration, mining dumps restoration, reforestation and agriculture. It will contribute to a more efficient use of materials and support important EU policy commitments reflected in the Roadmap to a Resource-Efficient Europe [2]. Furthermore, this will facilitate environmental integration of $\mathrm{CO}_{2}$ capture through the green economy of waste.

\section{Progress beyond the State-of-the-Art}

Fundamental properties of solid residues fly ash and bottom ash, from air-combustion and oxy-combustion

CFB combustion technology was developed to reduce $\mathrm{SO}_{\mathrm{x}}$ and $\mathrm{NO}_{\mathrm{x}}$ emissions, using limestone as bed sorbent material, and operating at lower temperatures (in the $800^{\circ} \mathrm{C}-900^{\circ} \mathrm{C}$ range) than Pulverised Coal combustion (PCC) $\left(1400^{\circ} \mathrm{C}\right)$. In CFB coal combustion two kinds of ash are produced: bottom ash extracted from the bottom of the boiler, and fly ash resulting from dust removal of the flue gas. Implementation of commercial CFB technology is not widespread as PCC, but some studies on $\mathrm{CFB}$ ash characterization have been carried out. $\mathrm{CFB}$ ashes are characterized by higher $\mathrm{Ca}, \mathrm{S}$ and unburned $\mathrm{C}$ content and lower glass proportion. Small scale studies on properties on ash produced by oxy-CFB and air-CFB showed some similar characteristics. Oxy-combustion ashes seem to be are characterized by lower glass content and C conversion. High occurrence of calcite and lime in oxy-combustion ash give involve high Ca concentrations in bottom ash (approx. 50\%) and in fly ash (4\% - 20\%) and to an alkaline $\mathrm{pH}$ of the leachates. As regards to environmental issues for oxy-fuel ashes, the content for most trace elements in oxy-CFB ashes are in the common range of CFB fly ash, displaying a low leachable potential (falling in the range of non-hazardous materials according to 2003/33/CE Council Decision for land-filling) [3] [4].

Oxy-fuel combustion technology is still under development and only few studies of small scale pilot CFB boiler (90 - $100 \mathrm{~kW})$ have been published [4] [5] [6]. The proposal will proposa the use of the larger oxy-CFB boiler in operation in the world, currently built in Ciuden (Spain), for industrial ash handling and real data acquisition and reuse.

Potential applications for oxy-combustion CFB ash valorisation

Coal combustion products (CCP) have been reused and valorised widely with success, for example for construction, civil engineering, agriculture, etc as mentioned by several ash associations like ADAA (Ash Development Association of Australia), UKQAA (UK Quality Ash Association) or ACAA (American Coal 
Ash Association), and usage of construction raw materials from coal institutions like ECOBA (European Coal Combusion Products Association). Nevertheless, the vast majority of ash products come from PCC boilers, which as mentioned before, have different characteristics than CFB ashes.

Novel and high added value applications of ash mainly include the synthesis of zeolite and geopolymers. Zeolites are materials with high cation exchange and molecular sieves capacity materials suitable for the metal uptake for soil and water remediation, and for the adsorption of gaseous pollutants. Also, K-zeolites have been tested as fertilizers. Geopolymers are high strength and low permeable materials, higher than cement and concrete, which can be used in the building industry and for encapsulate trace pollutants. Utilization of fly ash for ceramic manufacture, fire resistant material, foam glass (heat-insulating and soundproof material) and as a source for valuable elements have been tested with promising results. While the bottom ash and slag beneficial applications mainly include fine aggregate in asphalt paving; soil stabilization/waste solidification; raw material in concrete products; snow and ice traction control material.

Nevertheless some of the CFB ash characteristics may limit its use in some construction applications. The few number of studies of air-CFB ash have proven applications in agriculture, soil remediation, sludge stabilization, and in pavement construction applications [7] but also in the synthesis of zeolites. Nevertheless there are no studies on oxy-CFB ash applications.

With the completion of this project idea, a road map for the potential and most promising applications for oxy-combustion CFB bottom ash and fly ash will be readily available, including quantified recommendations on the possibilities of its absorbance into the European market.

Fundamental properties of oxy-combustion captured $\mathrm{CO}_{2}$ combined with algae production

The biofixation of $\mathrm{CO}_{2}$ by microalgae is based on the use of solar energy through photosynthesis to capture and use the $\mathrm{CO}_{2}$ produced by power stations or from other sources. This has been the subject of extensive investigations in the U.S., Japan and Europe (IEA-GHG Biofixation Network), especially as an option for the utilization of flue gases from power plants. However, none of the related projects have demonstrated the feasibility of the concept at a pre-industrial level. Even more, the $\mathrm{CO}_{2}$ fixation efficiency in the photobioreactors used in the pilot plants referred in the Biofixation Network report is low [8]. Typically 1.8 to 2 tonnes of $\mathrm{CO}_{2}$ will be utilised per tonne of algal biomass (dry) produced.

Algae utilization can have several applications such as: transportation fuel, livestock feed, agricultural fertilizer, pharmaceutical, metallurgical char, activated carbon, soil remediation, etc. The project idea will demonstrate on the field algae applications focused on agriculture as fertilizer and soil remediation, while addressing bioenergy and food applications.

On the other hand, the utilization of $\mathrm{CO}_{2}$ has been tested in agricultural practices in the past. Using $\mathrm{CO}_{2}$ increases the natural concentration of such in the 
controlled atmosphere of the greenhouse, as an additional nutrient for the plants. The project idea will test and validate the production of biomass from oxy-combustion captured $\mathrm{CO}_{2}$ as a fertilizer by injecting it into the ground in a controlled and safe manner.

Techno-economic assessment of valorisation of solid residues, fly ash and bottom ash, and algae production from oxy-combustion in CFB

A substantial amount of the coal combustion by-products (CCPs) produced worldwide (60\% of CCPs) is still disposed of in landfills and/or ponds at a significant cost to the utilizing consumers, and has caused significant environmental and economic burden. In the European Union (EU), approximately $5.6 \times$ $10^{7}$ tonnes of CCPs were produced in 2008, and fly ash represents the greatest proportion of total CCP production [9].

Published models to estimate the cost of capture, transport and storage [10] [11] can be used in combination to those published for Coal Combustion Products like ECOBA (EU) [12], ADAA (AUS) [13], and UKQAA (UK) [14] or the US EPA [15] or ACAA [16] (US) to provide the baselines for the economic assessment for this project and the viability for their uses while studying CCUS cost reduction, if it is the case. To perform valid and durable technical/economic trade-offs, fundamental knowledge on characterisation, possible valorisation and direct application must be incorporated along with economic assessments for the options of controlling or tolerating in utilities with CCUS, industrial and soil applications.

\section{Methodology and Associated Work Plan}

The proposed project structure is designed to enable good integration of research to be conducted by the partners allowing optimal information flow, extensive knowledge sharing and to some extent researchers mobility. Furthermore, SMEs contribution is promoted by the project enhancing field work between them. To avoid any duplication of work, the project will define specific tasks to.

Project proposal would comprise five stages (WP) as described below:

1) Project management and coordination of project work and results;

2) Oxy-CFB capture plant residues characterization;

3) Valorisation and reutilisation options analysis and recommendations for Oxy-CFB boiler fly ash, bottom ash and algae;

4) On the field tests for Oxy-CFB coal boiler fly ash and bottom ash, and algae;

5) Risk assessment; techno-economical and regulation conclusions and recommendations; dissemination and communication;

6) Exploitation and dissemination of project results.

\section{Expected Benefits}

Fly ash, bottom ash, captured $\mathrm{CO}_{2}$ and algae reutilization will contribute towards the sustainable supply of raw materials for economic markets in Europe. Fur- 
thermore, it will help to establish novel technologies, such as CFB boiler with CCUS by sustainability and green economy.

This collaborative research project, with the active participation of several SMEs, opens new fields of innovation and commercial products with new economic opportunities, and increases industrial capabilities about advanced materials and processing. It requires a multidisciplinary group and the impulse of innovation in SMEs.

Project approach is to work to align legislation on the various waste streams to improve coherence in the EU, facilitating the exchange of best practices and research on treatment of waste among Member States and develop measures to combat more effectively breaches of EU waste rules. This will help to achieve some of the goals of the Road Map to a Resource-efficient Europe by Horizon 2020 , like waste managed as a resource, or waste legislation fully implemented by 2020 .

The variety of partners and their involvement of some of them in current $\mathrm{Na}$ tional and European Research initiatives improve the communication and transfer of knowledge to stakeholders and general public. The communication plan will be designed to fill the gap between researcher, business and policy-makers interests. A complete dissemination activities agenda is envisaged to link the actions of the agents involved in the project, especially to move on the idea of opportunity for business or waste regulation. The bottom up impulse to a green economy and growth of employment based in this collaboration with SMEs and the sustainable use of waste advanced materials must be the core communication values to general public.

About $30 \%$ of the European power generation capacity is coal-fired and this percentage is much higher in certain EU countries (e.g. Poland, Czech Republic, Greece and Germany). Therefore, it can be predicted that in the long-term, coal will remain an important fuel in power generation in Europe. Nonetheless, conventional power production from coal is under pressure to reduce its carbon intensity. Additionally, Horizon 2020 aims to de-pollute by tackling the main sources of pollution: municipal waste, urban waste water and industrial pollution. The project will help to tackle both objectives, due to the enhancement of the deployment of CCUS, in combination with industrial de-pollution, urban waste elimination and waste water treatment to create new business opportunities.

An important ambition is to underpin an energy technology policy for Europe to accelerate the development and deployment of cost-effective low carbon technologies. By facilitating links to selected demonstration projects, this proposal implementation can benefit from realistic data, typical framework conditions and relevant cases provided by the demonstration projects which is essential for validating the scientific work.

There are several external factors like forest fires intensity, future biomass use, future food demand which may determine whether these impacts will be achieved. The implementation of this proposal will give solutions to the waste 
production of this installation which will derive into more sustainable consumption and production patterns and reduced environmental impacts while will help to develop new business models and industrial symbiosis.

\section{Dissemination and/or Exploitation of Project Results, and Management of Intellectual Property}

Dissemination and/or exploitation of project results

The first step on the communication and dissemination (C\&D) tasks will be to design a Communication plan to programme the information, message and timing of the C\&D actions, and to promote a regular flow of information. The information must be focussed on the technical and commercial achievements and the benefits they bring. It is important to define the targeted audiences. In this characterization the experience of the partners in the countries and its diversity will help to achieve the objectives of the project and also the goals that the EU tries to obtain. Covering a wide range of European Countries will help to translate the results of the project to a European common level. Dissemination will be compatible with intellectual property rights and confidentiality obligations of the partners.

Exploitation Plan-Main feature of the exploitation plan will be a SWOT analysis that will determine: Strength, Weakness, Opportunity and Threat of the results expected and also being adequate to the results obtained. Based on SWOT analysis, a business plan can be elaborated according to the results obtained.

Management of knowledge-Intellectual Property (IP)

Background IP-All background and related IP will be clearly identified by all partners, both prior to and during project implementation. Background (information including IP pertaining to its necessary for the project) shall remain the property of the participant who brings it into the project. Confidential background will be defined as such and treated as confidential by the partners with the option for the owner to have confidentiality agreements signed by the project partner requesting access rights to said confidential background.

Foreground IP-Each project partner will be the owner of the foreground and related IP it generates by its own efforts. Employees' and personnel rights will also be taken into consideration according to national law applicable. When foreground including the corresponding IP has been generated by common efforts (and it is not possible to ascertain individual contributions), participants shall have joint ownership of this foreground IP.

Access rights-All access rights requests will be made in writing. In some cases, access rights can be conditional on the acceptance of specific conditions for instance to grant an appropriate protection of the information to which access rights are granted. Implementation of access requests can be made throughout the project and will be granted royalty-free when needed for the purpose of the project. Access rights given for use can de requested up to one (1) 
year after the project end and will be granted royalty-free or on fair and reasonable conditions as applicable.

Licences-Joint owners of foreground may grant non-exclusive licences to third parties, subject to prior notice and fair and reasonable compensation to the other joint owners.

\section{Conflicts of Interest}

The authors declare no conflicts of interest regarding the publication of this paper.

\section{References}

[1] EC (2012) 2050 European Energy Roadmap. Publications Office of the European Union, Brussels.

[2] Roadmap to a Resource Efficient Europe. Brussels: s.n., 2011. COM(2011)571.

[3] ED (2003) 2003/33/EC: Council Decision of 19 December 2002 Establishing Criteria and Procedures for the Acceptance of Waste at Landfills Pursuant to Article 16 of and Annex II to Directive 1999/31/EC.

[4] Font, O., et al. (2011) Fate of Mercury and Other Trace Elements in an Oxy-Coal Combustion Pilot Plant. World of Coal Ash (WOCA) Conference, Denver, 9-12 May 2011.

[5] Jia, L., Tan, Y., Wang, C. and Anthony, E.J. (2007) Experimental Study of Oxy-Fuel Combustion and Sulfur Capture in a Mini-CFBC. Energy Fuels-American Chemical Society, 21, 3160-3164.

[6] IEAGHG (2010) Oxyfuel Combustion of Pulverised Coal, 2010/7. https://ieaghg.org/docs/General_Docs/Reports/2010-07.pdf

[7] Jackson, N.M., Schultz, S., Sander, P. and Schopp, L. (2009) Beneficial Use of CFB Ash in Pavement Construction Applications. Fuel, 88, 1210-1215.

https://doi.org/10.1016/j.fuel.2008.04.031

[8] IEA GHG and TNO (2009) Biofixation Network-IEAGHG-Carbon Capture and Storage.

[9] ECOBA. (2009). http://www.ecoba.com/

[10] IEA-GHG (2013) Toward a Common Method of Cost Estimation for $\mathrm{CO}_{2}$ Capture and Storage at Fossil fuel Power Plants. UK: s.n.

[11] ZEP-Zero Emission Fossil Fuel Plants. The Costs of $\mathrm{CO}_{2}$ Capture, Transport and Storage(2011), Report July 2011

https://hub.globalccsinstitute.com/sites/default/files/publications/17011/costs-co2-c apture-transport-and-storage.pdf

[12] ECOBA. (2018) http://www.ecoba.com/index.html

[13] ADAA (2007) Coal Combustion Products Handbook. http://www.adaa.asn.au/

[14] UKQAA. (2010) http://www.ukqaa.org.uk/

[15] US EPA (2010) Coal Ash (Coal Combustion Residuals, or CCR). https://www.epa.gov/coalash

[16] ACAA. (2010). https://www.acaa-usa.org/publications.aspx 